\title{
Power-Based Estimation of Cutting Forces During Turning of Aluminium Biomass Ash Particulate Composite
}

Emmanuella Emefe ( $\square$ emmanuella.emefe.fs08@unn.edu.ng )

University of Nigeria

Chigbogu Ozoegwu

University of Nigeria

Sylvester Edelugo

University of Nigeria

\section{Research Article}

Keywords: Cutting power, Force Coefficients, Cutting Forces, Aluminium biomass reinforced composites

Posted Date: December 8th, 2021

DOI: https://doi.org/10.21203/rs.3.rs-1118335/v1

License: (c) (i) This work is licensed under a Creative Commons Attribution 4.0 International License.

Read Full License 


\title{
Power-Based Estimation of Cutting Forces during Turning of Aluminium Biomass Ash Particulate Composite
}

\author{
${ }^{1 *}$ E.A. Emefe ${ }^{1,2}$ C.G. Ozoegwu ${ }^{1,2}$ S.O. Edelugo \\ ${ }^{1}$ Department of Mechanical Engineering, University of Nigeria, Nsukka. \\ ${ }^{2}$ African Centre of excellence, ACE-SPED, University of Nigeria, Nsukka \\ *E-mail: emmanuella.emefe.fs08@unn.edu.ng
}

\begin{abstract}
Aluminum-Biomass Ash Particulate Composite is a reinforced composite material of aluminum and biomass ash particles. The composite offers significant mechanical properties advantage and low-cost advantage because of the use of waste as the reinforcement material and as a result, it is gaining increased industrial attention because of the many advantages they offer over conventional Aluminium Matrix Composites. These materials are mostly accessed on the basis of their mechanical, microstructural and chemical properties with very limited interest on their machinability relative to the base material. The specific cutting force coefficients and cutting forces of the composite were estimated during CNC turning operations and the effects of reinforcement on the machinability responses were studied. In this work, power-based force estimation approach was adopted for this purpose for the first time. This approach is less expensive compared to the dynamometric approach since it relies on adapting existing equipment developed for other purposes. This was done by measuring the electric power of the direct-drive motors of the CNC machine during the turning process and the power measurements were analyzed to obtain the force coefficients. The cutting force components were observed to decrease as the percentage rice husk ash (RHA) reinforcement increased. This agrees with known results for the composite based on the dynamometric approach. Since the cutting force components decrease with increase in reinforcement, it can be deduced that increasing RHA in the Aluminium might reduce friction at the tool-chip interface and extend tool life, in other words, improving machinability. The composite therefore promises to be more cost effective than the base material in machinability terms.
\end{abstract}

Keywords: Cutting power, Force Coefficients, Cutting Forces, Aluminium biomass reinforced composites

\section{$1 \quad$ Introduction}

In practice, the cutting forces in the tangential, feed and radial directions find relevance in determining process accuracy and in calculating the resistance of various parts of machine tools. It is also useful in calculating the power of electric drive motors and in designing fixing devices for tools and materials. Moreover, the need for estimating the cutting forces arises from a number of factors, but perhaps the most important is detecting progress of tool wear, machining accuracy and machining system stability [1].

Accurate and reliable calculation of cutting force depends largely on a reasonable assessment of the cutting force coefficients. These coefficients rely on the cutting process, the cutting conditions (cutting feed, speed and depth of cut), the cutting tool (cutting edge geometry of the tool, tool material, coating, chip breaker, tool wear), the cutting fluid and the material of the workpiece 
(chemical composition, heat treatment) [2], [3]. Therefore, a single database of coefficients may be required in order to obtain a more accurate and reliable estimation of the specific cutting force coefficient, and this may involve calculating for the cutting force coefficient for each tool/material combination. Deng et al. [4] derived a theoretical formulae for calculating the cutting force for a cylindrical turning process using $\mathrm{C} 45$ carbon steel as the workpiece material and novel contact tools that have their chip/tool contact length inconstant and restricted. The minimal energy theory was used in these calculations. The findings of the detailed cutting experiments demonstrated that the derived theoretical formulae can estimate the cutting force during cylindrical turning of $\mathrm{C} 45$ carbon steel. Tsai et al. [5] studied the cutting forces generated during milling of Inconel 718. In order to estimate the cutting forces, the experimental set-up included a two-phase dry cut slot milling. A cutting force model for milling Inconel 718 was derived. Miroslav et al. [6] carried out an experimental investigation on the effects of cutting conditions on cutting forces during longitudinal turning of C60E steel. During the experiments, the tangential cutting force, the feed cutting force and the thrust (radial) cutting force were estimated. The feed, width of cut, tool cutting-edge angle, depth of cut and thickness of cut were found to affect cutting forces. The cutting force was also found to be influenced by the geometry of the cutting-edge and the material of the workpiece.

Nowadays, reinforced composites are gaining increased applications because of their enhanced mechanical properties. Thus, they are better substitutes for materials that are not reinforced. Nevertheless, manufacturing processes such as turning, milling drilling and grinding still need to be carried out on MMCs so as to obtain the required part types and sizes [7].

As alluded earlier, cutting forces play a major role in machining processes as they affect workpiecetool deflection [8], part quality and machine tool vibration [9], [10]. Accurate force estimation in turning is therefore an important factor in process optimization, process characterization and machining performance enhancement [3].

Estimation of cutting forces is necessary to estimate the required cutting power of a machine tool and to estimate the cutting force on machine tool components such as bearings, jigs, and fixtures.

Purushothaman et al [11] investigated on the cutting force and surface roughness in machining 6068 Aluminium alloy. The tangential, feed and thrust cutting forces were measured from a lathe tool dynamometer. The relationship between the cutting parameters (the feed rate, revolution per minute (RPM) and depth of cut) and cutting forces were established from the results of the experiment. From the results of the experiment, cutting force increased with increased feed, when the depth of cut was kept constant.

Miroslav et al. [6] carried out an experimental investigation on the effects of cutting conditions on cutting forces during longitudinal turning of C60E steel. During the experiments, the tangential, the feed and the radial cutting forces were estimated. The feed, tool cutting-edge angle, depth of cut and thickness of cut were found to affect cutting forces. The cutting force was also found to be influenced by the geometry of the cutting-edge and the material of the workpiece.

Shoba et al. [12] studied the effects of reinforcement on cutting forces. He used rice_RHA and $0,2,4,6$ and 8 wt. \% silicon carbide $(\mathrm{SiC})$ particles as the reinforcing material and A356.2 Al alloy as the base material. A Kistler dynamometer was used for the force measurement. From the experimental result, during machining of low weight percentage reinforced MMCs, built-up edge (BUE) is formed 
during machining at high speed and large depth of cut.

\section{The Linear Cutting Force Law}

The cutting force, $F$ in turning can be expressed as a product of the specific cutting force coefficient, $K$ and the area of cut, $A$ [13] as shown in the equation (1);

$$
F=K A
$$

The area of cut is given as $A=a_{p} f_{r}$ where $a_{p}$ is the depth of cut and $f_{r}$ is the feed (or chip thickness for orthogonal cutting). The most adopted method of cutting force measurements is the use of a dynamometer. The calculations of the specific cutting force coefficients are made by fitting a function between feed and cutting force in any of the tangential, feed and thrust force directions [14]. This is expressed as follows;

$$
\begin{aligned}
& F_{t}=K_{t c} a_{p} f_{r}+K_{t e} a_{p} \\
& F_{f}=K_{a c} a_{p} f_{r}+K_{a e} a_{p} \\
& F_{n}=K_{n c} a_{p} f_{r}+K_{n e} a_{p}
\end{aligned}
$$

where $F_{t}$ is the tangential cutting force in $\mathrm{N}, F_{f}$ is the feed cutting force in $\mathrm{N}, F_{n}$ is the thrust (radial) cutting force in $\mathrm{N}, K_{t c}$ is the tangential cutting force coefficient in $\mathrm{N} / \mathrm{m}^{2}, K_{t e}$ is the tangential edge force coefficient in $\mathrm{N} / \mathrm{m}, K_{f c}$ is the feed cutting force coefficient in $\mathrm{N} / \mathrm{m}^{2}, K_{f e}$ is the feed edge force coefficient in $\mathrm{N} / \mathrm{m}, K_{n c}$ is the thrust (radial) cutting force coefficient in $\mathrm{N} / \mathrm{m}^{2} ; K_{n e}$ is the thrust edge force coefficient in $\mathrm{N} / \mathrm{m}$.

Qiu [15] modeled the force coefficients in cylindrical turning of 5140 steel and cast iron based on power measurement. The results from a force dynamometer was compared with the result based on power measurement. The cutting force measurement results based on power measurement showed good correlation with the results obtained from the force dynamometer. The method established in this study is adapted in the current research.

Mohamad [16] analyzed energy in turning and milling based on power measurement. A clamp meter was used to measure the current during machining with a $\mathrm{CNC}$ lathe machine. The power drawn by the three-phase electric motor was calculated using equation (5)

$$
P=V I \sqrt{3}
$$

where $P$ is the power drawn by the electric motor, $I$ is the electrical current and $V$ is the voltage.

\section{Power-based Calculation Models of Cutting Force Coefficients}

\subsection{Calculation Model of Tangential Cutting Force Coefficient}

Spindle Cutting Power, $P_{m s}$ is a product of tangential cutting force, $F_{t}$ and cutting speed, $v_{c}$ [17]. Therefore, the spindle cutting power in turning the workpiece can therefore be expressed as follows;

$P_{m s}=F_{t} v_{c}=\frac{\pi D \Omega_{s}}{60}\left(K_{t c} f_{r} a_{p}+K_{t e} a_{p}\right)$

where $F_{t}$ is the tangential cutting force in $\mathrm{N}, v_{c}=$ $\pi D \Omega_{s} / 60$ is the cutting speed in $\mathrm{m} / \mathrm{s}, D$ is the diameter of the workpiece in $\mathrm{m}, \Omega_{s}$ is the spindle speed in rpm. But, $\Omega_{s}=\Omega_{m} / i$, where, $\Omega_{m}$ is the motor speed and $i$ is the ratio of transmission from motor to spindle. $K_{t c}$ is the tangential cutting force coefficient in $\mathrm{N} / \mathrm{m}^{2}, f_{r}$ is the feed in $\mathrm{m} / \mathrm{r}, a_{p}$ is the depth of cut in $\mathrm{m}, K_{t e}$ is the edge force coefficient of the tangential cutting force in $\mathrm{N} / \mathrm{m}^{2}$.

The power input of the motor spindle, $P_{m s}$ is a sum of the motor power used for cutting, $P_{m c}$ and the power loss of motor spindle, $P_{S 0}[15]$ and can be expressed as;

$$
P_{m s}=P_{m c}+P_{s 0}
$$


The power loss of motor spindle, $P_{s 0}$ is approximately equal to the idle spindle power.

The Material Removal Rate in $\mathrm{m}^{3} / \mathrm{s}$ [18] can be expressed as follows;

$$
M R R=\frac{\pi D \Omega_{s}}{60} a_{p} f_{r}
$$

since cutting speed, $v_{c}=\frac{\pi D \Omega_{s}}{60}$ in $\mathrm{m} / \mathrm{s}$.

Therefore, combining equations (6), (7) and (8), the motor spindle power, $P_{m s}$ can be further written as;

$P_{m s}=K_{t c} M R R+K_{t e} \frac{\pi D \Omega_{s}}{60} a_{p}+P_{s 0}$

This is a linear equation in $M R R$ from which $K_{t c}$ and $K_{t e}$ can be extracted.

Equation (9) can be re-written as;

$P_{m c}=P_{m s}-P_{s 0}=K_{t c} M R R+K_{t e} \frac{\pi D \Omega_{s}}{60} a_{p}$

showing that $K_{t c}$ is the slope $S_{x}$ of $P_{m c}$ against $M R R$ and $K_{t e}=I_{x} / \frac{\pi D \Omega_{s}}{60} a_{p}$ where $I_{x}$ is the intercept.

\subsection{Calculation Model of Feed Cutting Force Coefficient}

The following equations can be useful in calculating for the feed cutting force coefficients [15].

$$
\begin{aligned}
P_{m z} & =P_{z c}+P_{z 0} \\
F_{f} & =60 \frac{P_{z c}}{\Omega_{s} f_{r}}
\end{aligned}
$$

where $P_{m z}$ is the power input of the axial feed motor, $P_{z c}$ is the feed axis cutting motor power, $P_{z 0}$ is the feed axis motor power loss $F_{f}$ is the feed axis cutting force in $\mathrm{N}$.

Inserting equations (3) and (12), the power input can be further expressed as;

$$
P_{m z}=\frac{K_{a c} a_{p} \Omega_{s}}{60} f_{r}^{2}+\frac{K_{a e} a_{p} \Omega_{s}}{60} f_{r}+P_{z 0}
$$

Equation (13) can be re-written as;

$\frac{P_{z c}}{f_{r}}=\frac{P_{m z}-P_{z 0}}{f_{r}}=\frac{K_{a c} a_{p} \Omega_{s}}{60} f_{r}+\frac{K_{a e} a_{p} \Omega_{s}}{60}$

showing that $K_{a c}=S_{z} / \frac{a_{p} \Omega_{s}}{60}$ and $K_{a e}=I_{z} / \frac{a_{p} \Omega_{s}}{60}$ where $S_{z}$ and $I_{z}$ are the slope and intercept of the graph of $\frac{P_{z c}}{f_{r}}$ against $f_{r}$.

\subsection{Calculation Model of Radial Cutting Force Coefficients}

During orthogonal machining operation, the thrust force can be expressed as follows [15];

$$
F_{n}=F_{t} \tan (\beta-\alpha)
$$

Hence, the coefficients of the radial cutting force can be expressed as;

$$
\begin{aligned}
& K_{n c}=K_{t c} \tan (\beta-\alpha) \\
& K_{n e}=K_{t e} \tan (\beta-\alpha)
\end{aligned}
$$

where $F_{n}$ is the thrust force in $\mathrm{N}, F_{t}$ is the tangential cutting force in $\mathrm{N} ; K_{n c}$ is the thrust cutting force coefficient in $\mathrm{N} / \mathrm{m}^{2}, K_{n e}$ is edge thrust force coefficient in $\mathrm{N} / \mathrm{m}^{2}, \beta$ is the chip friction angle, $\alpha$ is the rake angle.

The chip friction angle can be calculated from force measurement by statistical analysis of the data of experiment. The empirical formulae for the determination of chip friction angle [15] is shown below;

$$
\beta=\arctan \left(\frac{F_{p i}}{F_{t i}}\right)+\alpha
$$

where $F_{p i}$ is the average thrust force in $\mathrm{N}$ and $F_{t i}$ is the average tangential cutting force in $\mathrm{N}$.

\section{Experimental Method and Procedure}

\subsection{Workpiece Material Composition}

The workpiece material includes a control material of Aluminium without reinforcement and Aluminium with 3\%, 6\%, $9 \%$ and $12 \%$ rice-husk reinforcements. The Aluminium was sourced from Cutix Plc. The 
chemical composition of the Aluminium

shown in Table 1. The chemical composition material as provided by the company is

of the rice-husk is shown in Table 2.

Table 1 - Aluminium Chemical Composition

\begin{tabular}{lllllllllllll}
\hline Constituent & $\mathbf{S i}$ & $\mathbf{C u}$ & $\mathbf{M g}$ & $\mathbf{F e}$ & $\mathbf{M n}$ & $\mathbf{C r}$ & $\mathbf{Z n}$ & $\mathbf{V}$ & $\mathbf{T i}$ & $\mathbf{B}$ & $\mathbf{G a}$ & $\mathbf{A l}$ \\
\hline $\begin{array}{l}\text { Percentage } \\
\text { (wt\%) }\end{array}$ & 0.10 & 0.05 & 0.03 & 0.40 & 0.01 & 0.01 & 0.05 & 0.02 & 0.02 & 0.05 & 0.03 & 99.5 \\
\end{tabular}

Table 2 - Rice-Husk Ash Chemical Composition [19]

\begin{tabular}{lllllllll}
\hline Constituent & $\mathrm{SiO}_{2}$ & $\mathrm{Fe}_{2} \mathrm{O}_{3}$ & $\mathrm{Al}_{2} \mathrm{O}_{3}$ & $\mathrm{MgO}$ & $\mathrm{CaO}$ & $\mathrm{K}_{2} \mathrm{O}$ & $\mathrm{N}_{2} \mathrm{O}$ & $\mathrm{LOI}$ \\
\hline $\begin{array}{l}\text { Percentage } \\
\text { (wt\%) }\end{array}$ & 94.04 & 0.136 & 0.249 & 0.442 & 0.622 & 2.49 & 0.023 & 3.52 \\
\hline
\end{tabular}

\subsection{Experimental procedure}

Turning operation was carried out on the workpiece material using a CNC machine. The experimental procedure was carried out at the Nigerian Liquefied Natural Gas (NLNG) laboratory, University of Nigeria, Nsukka (UNN), Nigeria using the 250PCi Boxford CNC lathe machine manufactured by Boxford holdings ltd, England with spindle motor rating of $2.9 \mathrm{hp}$. The cutting parameters used during the experimental procedure are as follows: Feed: $0.015,0.03,0.045,0.060,0.075 \mathrm{~mm} / \mathrm{rev}$; Depth of cut: $0.5 \mathrm{~mm}$; Spindle Speed: 100rpm. The spindle and feed motor currents were measured and recorded during the experimental testing. The idle spindle and feed motor currents were also measured and recorded using a digital clamp meter. The voltage was also measured to be $220 \mathrm{~V}$ using a custom-made power meter. Equation (5) was used to calculate the spindle and feed powers drawn by the electric motors. The experimental setup is shown in figure 1 and the tool material used is cemented carbide insert whose geometry and specification is shown in Table 3.

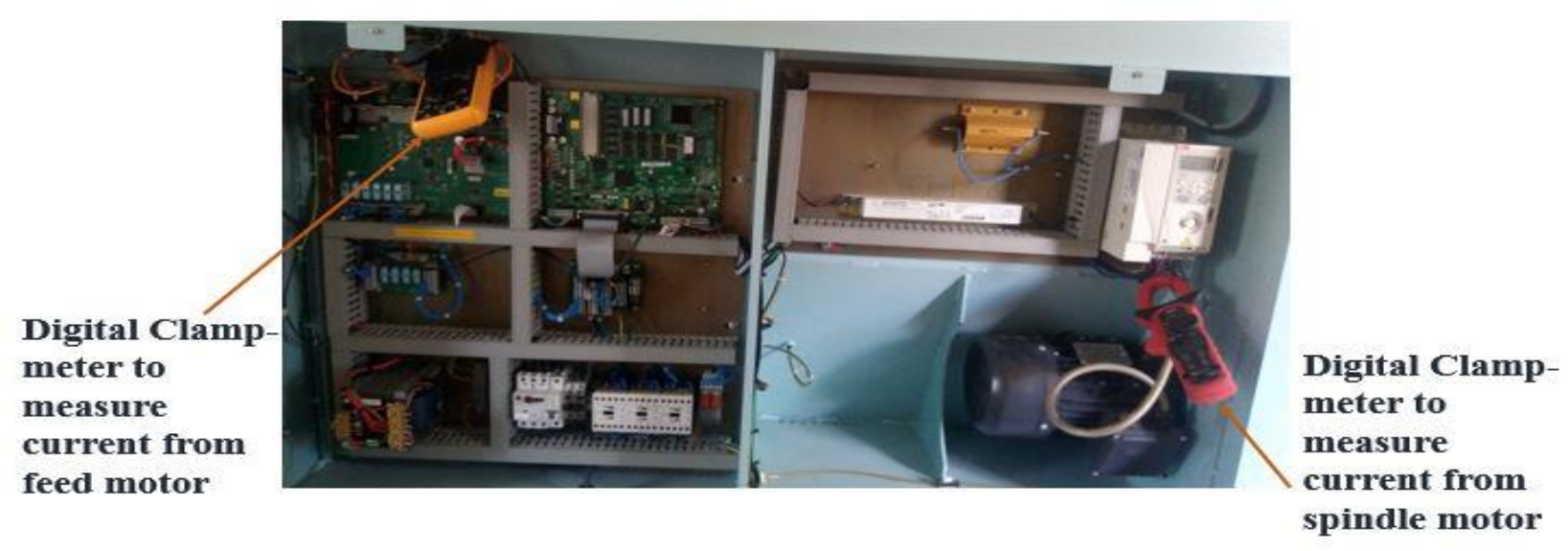

Figure 1 - Experimental set-up 
Table 3 - Cutting Tool Specification

\begin{tabular}{ll}
\hline Cutting tool type & Cemented carbide \\
\hline Tool holder & CTANR 2525-M16 \\
\hline Specification & SNMG 120408 \\
\hline Geometry of tool & $0-10-6-6-8-75-1 \mathrm{~mm}$ \\
\hline Condition of Cutting & Dry \\
\hline
\end{tabular}

\section{$5 \quad$ Results and Discussion}

\subsection{Specific Cutting Force Coefficient}

The specific cutting force coefficient in the tangential and feed directions were calculated using equations (10) and (14) respectively. The slope and intercept were used to obtain the specific cutting and edge force coefficients in the tangential and feed directions respectively. The thrust specific cutting and edge force coefficients were obtained from equation (16) and (17) respectively. The estimated force coefficients are summarized in Table 4.

Table 4 - Calculated specific Cutting and Edge Force Coefficients from Slope and Intercept

\begin{tabular}{|l|l|l|l|l|l|l|l|l|}
\hline $\begin{array}{l}\% \\
\begin{array}{l}\text { Rein- } \\
\text { force } \\
\text { ment }\end{array}\end{array}$ & \multicolumn{1}{|c|}{$S_{x}$} & $I_{x}$ & $K_{t c}=S_{x}$ & $\begin{array}{l}K_{t e} \\
=I_{x} / \frac{\pi D \Omega_{s}}{60} a\end{array}$ & $S_{z}$ & $I_{z}$ & $K_{a c}=S_{z} / \frac{a_{p} \Omega_{s}}{60}$ & $\begin{array}{l}K_{a e} \\
=I_{z} / \frac{a_{p} \Omega_{s}}{60}\end{array}$ \\
\hline 0 & 782940802.04 & 4.815 & 782940802.04 & 91947.80 & 327079 & 38.421 & 392494872.9 & 46105.37951 \\
\hline 3 & 920432845.32 & 4.033 & 920432845.32 & 77014.64 & 425299 & 27.201 & 510358872.9 & 32641.41951 \\
\hline 6 & 855506047.10 & 3.834 & 855506047.10 & 73214.51 & 435079 & 20.468 & 522094872.9 & 24561.37951 \\
\hline 9 & 822406110.76 & 3.29 & 822406110.76 & 62826.23 & 397746 & 15.774 & 477294872.9 & 18929.37951 \\
\hline 12 & 831317632.08 & 2.973 & 831317632.08 & 56772.76 & 307079 & 12.84 & 368494872.9 & 15409.37951 \\
\hline
\end{tabular}

These specific force coefficients were inserted into power models i.e., equations (9) and (13). The predicted values from the model equations were plotted against the measured values and an acceptable $\mathrm{R}^{2}$ values of $99.86 \%$ and $90.46 \%$ were obtained for the plot of spindle and feed power respectively. The very high $\mathrm{R}^{2}$ values show that the calibrated force coefficients are accurate.

Figures $2 \mathrm{a}$ and $\mathrm{b}, 3 \mathrm{a}$ and $\mathrm{b}$ and $4 \mathrm{a}$ and $\mathrm{b}$ shows the graph of the specific cutting forces in the tangential $\left(K_{t c}, K_{t e}\right)$, feed $\left(K_{a c}, K_{a e}\right)$ and thrust directions $\left(K_{n c}, K_{n e}\right)$ respectively with respect to the percentage reinforcement. From figures (2a and $b$ ), the specific cutting force in the tangential direction increased and fell and the turning point is in the range of the $3 \%-6 \%$ reinforcements. The edge cutting force coefficients decreased as percentage reinforcement increased. From figures $3 a$ and $b$ and $4 a$ and $b$, the specific cutting force in the feed and thrust directions increased and then decreased with increase in reinforcement, and the turning point is in the range of the $3 \%-6 \%$ reinforcements. The edge cutting force decreased as percentage reinforcement increased. The decrease in edge force coefficients as percentage reinforcement 
increased might be as a result of the dislocation densities formed from the thermal difference between the matrix and the reinforcement [12].

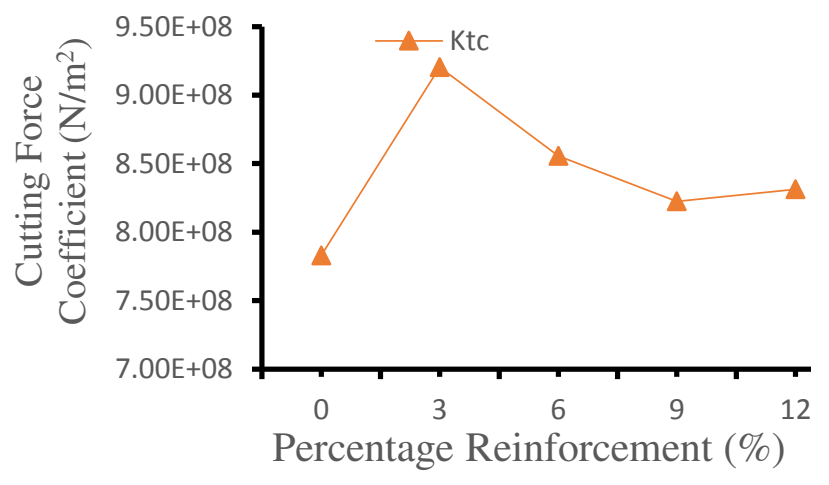

Figure 2a - Plot of Specific Cutting Force in the Tangential Direction with respect to the Percentage Reinforcement

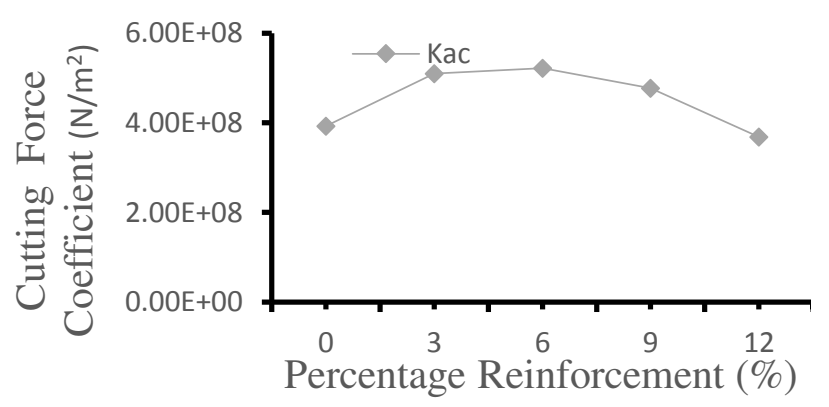

Figure 3a - Plot of Specific Cutting Force in the Feed Direction with respect to the Percentage Reinforcement
This decrease also may have contributed to the decrease in cutting force, since the force coefficients are used to obtain the cutting forces.

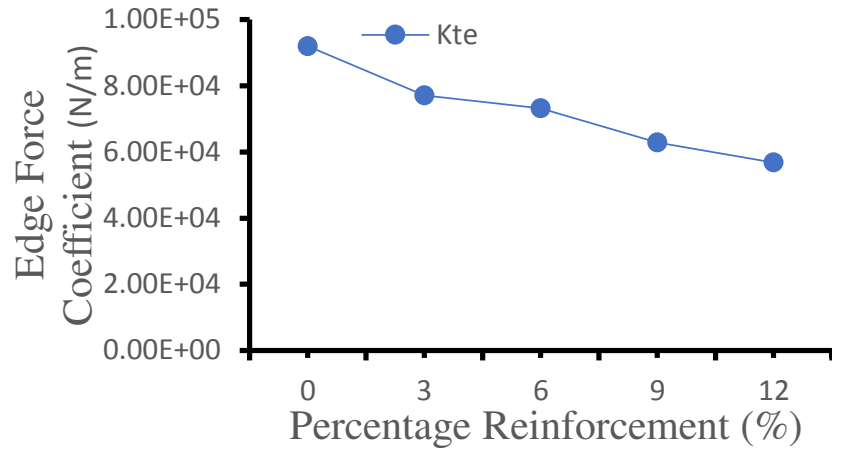

Figure 2b - Plot of Specific Edge Force in the Tangential Direction with respect to the Percentage Reinforcement

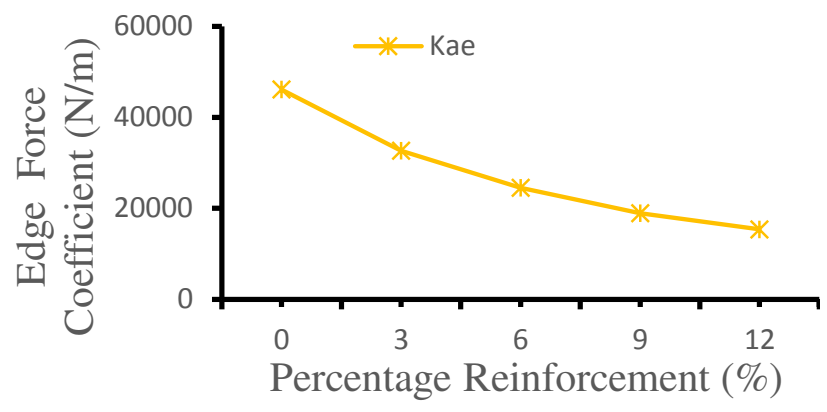

Figure 3b - Plot of Specific Edge Force in the Feed Direction with respect to the Percentage Reinforcement 


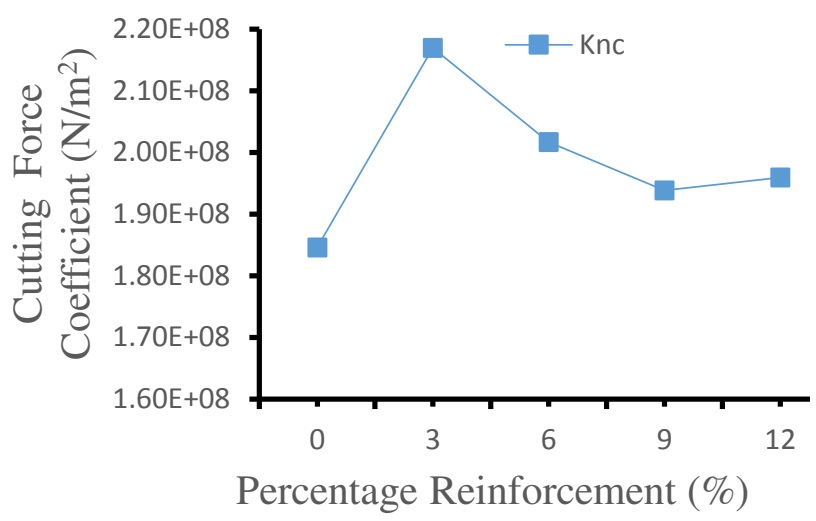

Figure 4a - Plot of Specific Cutting Force in the Thrust Direction with respect to the Percentage Reinforcement

\subsection{Cutting Forces}

The cutting forces in the tangential, feed and thrust directions were estimated using equations (2), (3) and (4) respectively. The graphs of the cutting force in the tangential, feed and thrust directions with respect to the feed are shown in figures $5 \mathrm{a}, 5 \mathrm{~b}$ and $5 \mathrm{c}$ respectively. Cutting forces are seen to rise with feed because of force proportionality with undeformed chip crosssectional area. From figures $5 \mathrm{a}, 5 \mathrm{~b}$ and $5 \mathrm{c}$, the cutting force components are observed to decrease as the percentage reinforcement increases. This agrees with the research of Shoba

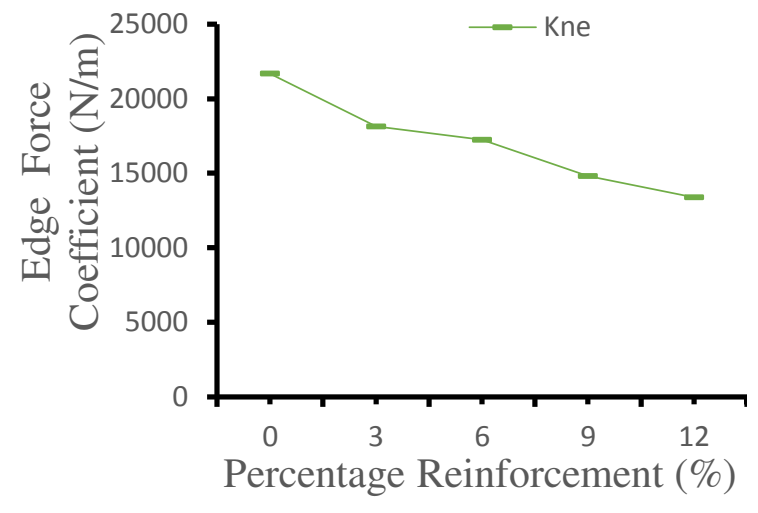

Figure 4b - Plot of Specific Edge Force in the Thrust Direction with respect to the Percentage Reinforcement
[12] whose study was on A356.2 Aluminium Alloy reinforced with RHA using a dynamometric force measurement approach. From his study, the cutting force components are lower for the reinforced composites than unreinforced alloy and this was as a result of the dislocation densities formed from the thermal difference between the matrix and the reinforcement. From figures $5 \mathrm{a}, 5 \mathrm{~b}$ and $5 \mathrm{c}$, it can be deduced that increasing RHA in the Aluminium might reduce friction at the tool chip interface and extend tool life. In other words, improving machinability.

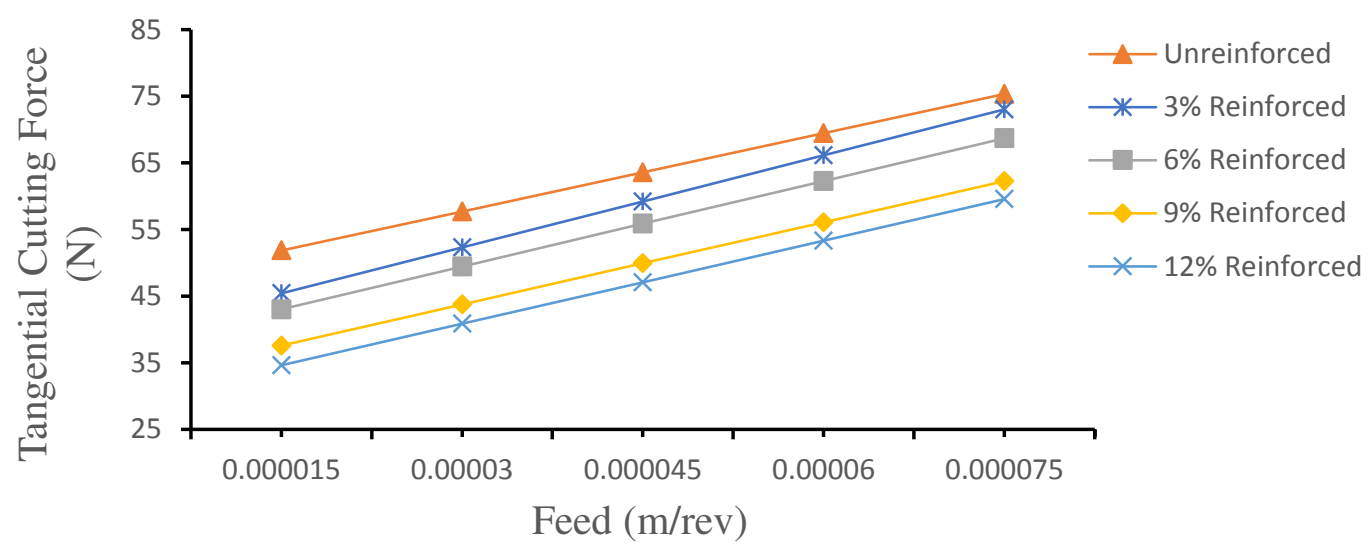

Figure 5a-Plot of $\boldsymbol{F}_{\boldsymbol{t}}$ against $\boldsymbol{f}_{\boldsymbol{r}}$ 


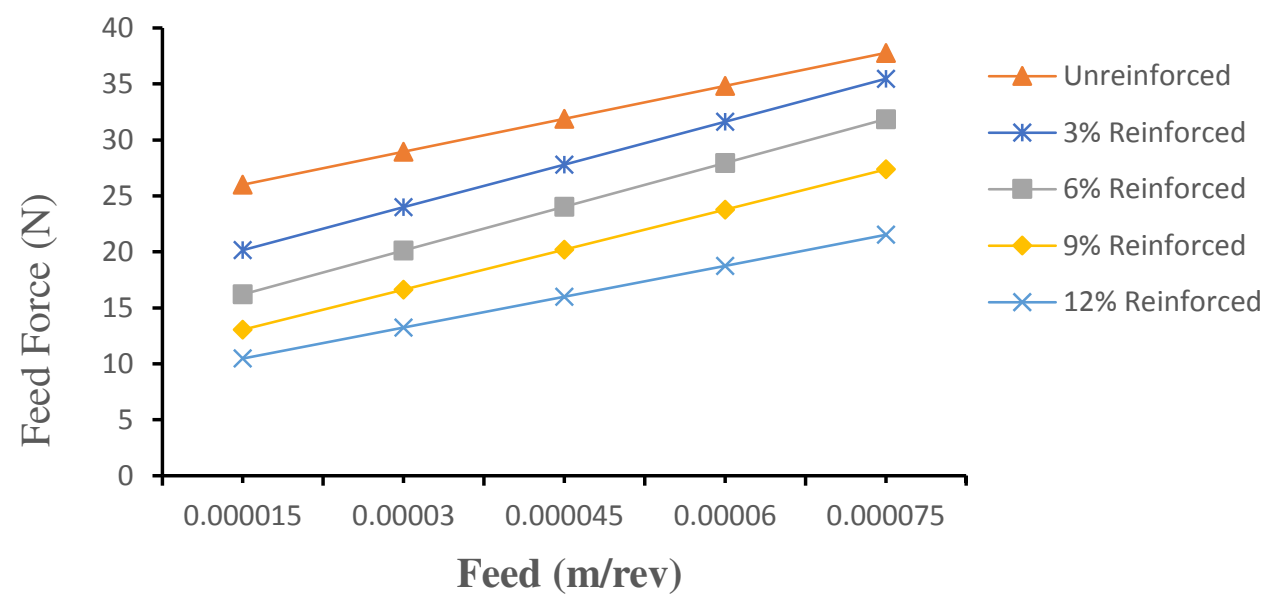

Figure 5b-Plot of $F_{f}$ against $f_{r}$

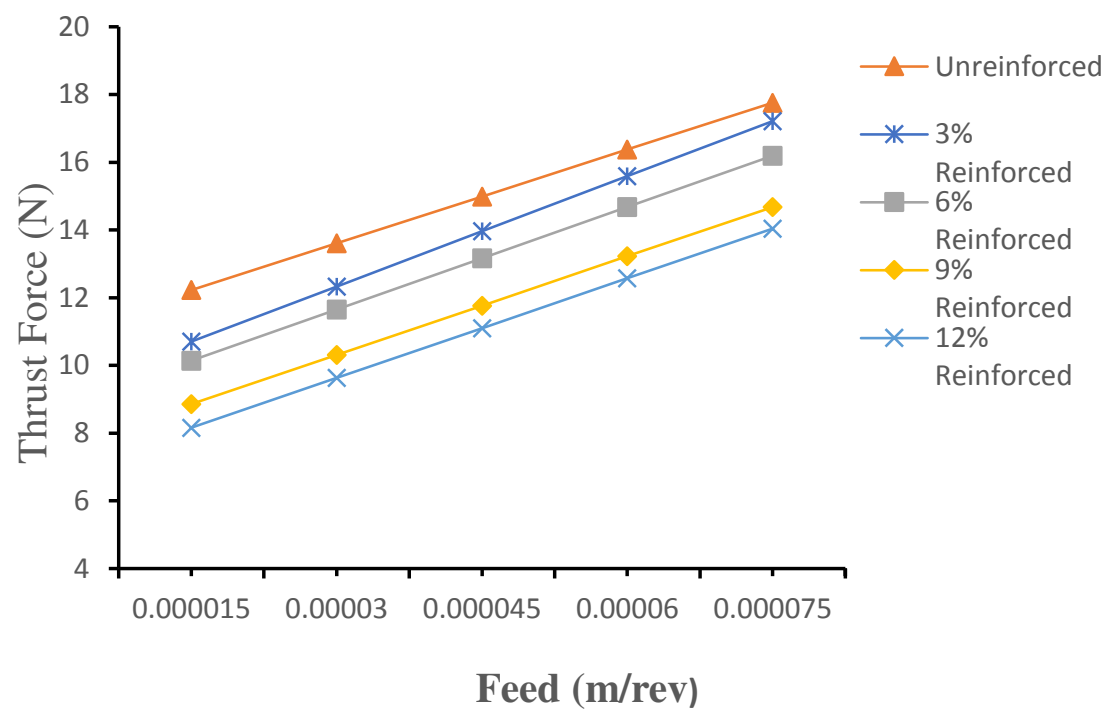

Figure 5c-Plot of $F_{n}$ against $f_{r}$

\subsection{Calculation of Cutting Force}

Table 5 shows the developed empirical equations for calculating the cutting force in the tangential $\left(F_{t}\right)$, feed $\left(F_{f}\right)$ and thrust $\left(F_{n}\right)$ directions. These force models were derived from the specific cutting force coefficients obtained during machining of the studied Aluminium rice-husk reinforced composites. These force models are considered very accurate because of the very high $\mathrm{R}^{2}$ values between the measured and predicted cutting powers. The developed force models can be used in further analysis like chatter [20], tribological and deflection analysis of the turning processes of the composites. 
Table 5 - Cutting Force Model

\begin{tabular}{|c|c|c|c|c|c|}
\hline $\begin{array}{l}\% \\
\text { Reinforcement }\end{array}$ & Force Model & $\begin{array}{l}\text { Feed, } \\
\mathrm{mm} / \mathrm{r}\end{array}$ & $\begin{array}{l}F_{t}, \\
N\end{array}$ & $\begin{array}{l}F_{f}, \\
N\end{array}$ & $\begin{array}{l}F_{n}, \\
N\end{array}$ \\
\hline \multirow[t]{5}{*}{$0 \%$} & \multirow{5}{*}{$\begin{array}{c}F_{t}=782940802.04 a_{p} f_{r}+91947.80 a_{p} \\
F_{f}=392494872.9 a_{p} f_{r}+46105.3795 a_{p} \\
F_{n}=184607924.6 a_{p} f_{r}+21680.1746 a_{p}\end{array}$} & 0.015 & 51.85 & 25.996 & 12.225 \\
\hline & & 0.030 & 57.72 & 28.940 & 13.605 \\
\hline & & 0.045 & 63.59 & 31.884 & 14.990 \\
\hline & & 0.060 & 69.46 & 34.828 & 16.374 \\
\hline & & 0.075 & 75.33 & 37.771 & 17.758 \\
\hline \multirow[t]{5}{*}{$3 \%$} & \multirow{5}{*}{$\begin{array}{c}F_{t}=920432845.32 a_{p} f_{r}+77014.64 a_{p} \\
F_{f}=510358872.9 a_{p} f_{r}+32641.4195 a_{p} \\
F_{n}=216965199.2 a_{p} f_{r}+18153.9554 a_{p}\end{array}$} & 0.015 & 45.41 & 20.148 & 10.704 \\
\hline & & 0.030 & 52.31 & 23.976 & 12.331 \\
\hline & & 0.045 & 59.22 & 27.804 & 13.959 \\
\hline & & 0.060 & 66.12 & 31.631 & 15.586 \\
\hline & & 0.075 & 73.02 & 35.459 & 17.213 \\
\hline \multirow[t]{5}{*}{$6 \%$} & \multirow{5}{*}{$\begin{array}{c}F_{t}=855506047.10 a_{p} f_{r}+73214.51 a_{p} \\
F_{f}=522094872.9 a_{p} f_{r}+24561.3795 a_{p} \\
F_{n}=201660600.1 a_{p} f_{r}+17258.1862 a_{p}\end{array}$} & 0.015 & 43.02 & 16.196 & 10.142 \\
\hline & & 0.030 & 49.44 & 20.112 & 11.654 \\
\hline & & 0.045 & 55.86 & 24.028 & 13.166 \\
\hline & & 0.060 & 62.27 & 27.944 & 14.679 \\
\hline & & 0.075 & 68.69 & 31.859 & 16.191 \\
\hline \multirow[t]{5}{*}{$9 \%$} & \multirow{5}{*}{$\begin{array}{c}F_{t}=822406110.76 a_{p} f_{r}+62826.23 a_{p} \\
F_{f}=477294872.9 a_{p} f_{r}+18929.3795 a_{p} \\
F_{n}=193858255.5 a_{p} f_{r}+14809.4503 a_{p}\end{array}$} & 0.015 & 37.58 & 13.044 & 8.859 \\
\hline & & 0.030 & 43.75 & 16.624 & 10.313 \\
\hline & & 0.045 & 49.92 & 20.204 & 11.767 \\
\hline & & 0.060 & 56.09 & 23.784 & 13.220 \\
\hline & & 0.075 & 62.25 & 27.363 & 14.674 \\
\hline \multirow[t]{5}{*}{$12 \%$} & \multirow{5}{*}{$\begin{array}{c}F_{t}=831317632.08 a_{p} f_{r}+56772.76 a_{p} \\
F_{f}=368494872.9 a_{p} f_{r}+15409.3795 a_{p} \\
F_{n}=195958886.78 a_{p} f_{r}+13382.5215 a_{p}\end{array}$} & 0.015 & 34.62 & 10.468 & 8.161 \\
\hline & & 0.030 & 40.86 & 13.232 & 9.631 \\
\hline & & 0.045 & 47.09 & 15.996 & 11.100 \\
\hline & & 0.060 & 53.33 & 18.760 & 12.570 \\
\hline & & 0.075 & 59.56 & 21.523 & 14.040 \\
\hline
\end{tabular}




\section{Conclusion and Recommendations}

\subsection{Conclusion}

The specific cutting force coefficients and the cutting forces during machining of Aluminium rice husk ash reinforced-composite were obtained using the power-based method of force estimation. The edge force coefficients decreased with increase in reinforcement. The decrease in edge force coefficients might be as a result of the dislocation densities formed from the thermal difference between the matrix and the reinforcement [12] and the fact that addition of the harder ash particles makes the composite harder relative to the base material, therefore reducing rubbing surface area at the rake and flank. This manifested as decrease in the edge force coefficients with increasing reinforcement.

The cutting force components are observed to decrease as the percentage reinforcement increases. This agrees with the research of Shoba [12] whose study was on A356.2 Aluminium Alloy reinforced with RHA using a dynamometric approach. From his study, the cutting force components are lower for the reinforced composites than unreinforced alloy. Since the cutting force components decrease with increase in reinforcement, it can be deduced that increasing RHA in the Aluminium might reduce friction at the tool-chip interface and extend tool life. In other words, improving machinability.

Cutting forces and specific cutting force coefficients are very important criteria when it comes to machinability. The specific cutting force coefficient and the cutting force have direct influence on the energy needed for machining. The studied composite is therefore more cost effective than the unreinforced Aluminium in terms of machinability. There is also a possible tool life improvement for the reinforced composite compared to the unreinforced composite.

\subsection{Recommendations}

The implications of reinforcing Aluminium with rice husk ash should be analyzed further for sustainability and energy-based economics effectiveness.

The effect of rice husk ash reinforcement of Aluminium on the tool life and tool wear can also be studied.

The developed cutting force coefficients can be used in further analysis like chatter, tribological and deflection analysis of the turning processes of the composites.

Acknowledgement: The authors would like to appreciate Deutscher Akademischer Austauschdienst (German Academic Exchange Service) for their support and sponsorship.

\section{References}

[1] B. W. Ikua, H. Tanaka, F. Obata, S. Sakamoto, T. Kishi, and T. Ishii, "Prediction of cutting forces and machining error in ball end milling of curved surfaces -II experimental verification," Precis. Eng., vol. 26, no. 1, pp. 69-82, 2002.
[2] A. Lamikiz, L. N. Lopez De Lacalle, J. A. Sanchez, and U. Bravo, "Calculation of the specific cutting coefficients and geometrical aspects in sculptured surface machining," Mach. Sci. Technol., vol. 9, no. 3, pp. 411-436, 2005.

[3] T. C. Bera, H. Manikandan, A. Bansal, 
and D. Nema, "A Method to Determine Cutting Force Coefficients in Turning Using Mechanistic Approach," Int. J. Mater. Mech. Manuf., vol. 6, no. 2, pp. 99-103, 2018.

[4] W. J. Deng, Q. Li, B. L. Li, Y. T. He, W. Xia, and Y. Tang, "Study on the cutting force of cylindrical turning with novel restricted contact tools," Int. J. Adv. Manuf. Technol., vol. 69, no. 5-8, pp. 1625-1638, 2013.

[5] J. C. Tsai, C. Y. Kuo, Z. P. Liu, and K. H. H. Hsiao, "An investigation on the cutting force of milling Inconel 718," MATEC Web Conf., vol. 169, pp. 1-8, 2018.

[6] R. Ć. Miroslav, D. Ć. Predrag, and J. Ć. Predrag, "Experimental Determination of Cutting Force By Longitudinal Turning of C60E Steel," Rom. Tech. Sci. Acad., vol. 2, no. August 2017, pp. 113-119, 2006.

[7] C. R. P. Rao and M. S. Bhagyashekar, "Effect of Machining Parameters on the Surface Roughness while Turning," Procedia Eng., vol. 97, no. February 2015, pp. 421-431, 2014.

[8] B. P. Mann, B. T. Edes, S. J. Easley, K. A. Young, and K. Ma, "Chatter vibration and surface location error prediction for helical end mills," Int. J. Mach. Tools Manuf., vol. 48, no. 3-4, pp. 350-361, Mar. 2008.

[9] C. Ozoegwu and P. Eberhard, "Stability Analysis of Multi-Discrete Delay Milling with Helix Effects Using a General Order Full-Discretization Method Updated with a Generalized Integral Quadrature," Math. 2020, Vol. 8, Page 1003, vol. 8, no. 6, p. 1003, Jun. 2020.

[10] C. Ozoegwu and P. Eberhard, "Automated Upgraded Generalized FullDiscretization Method: Application to the Stability Study of a Thin-Walled Milling Process," Mech. Sci., pp. 83-104, 2021.

[11] D. Purushothaman, K. K. Yanamundra,
G. Krishnan, and C. Perisamy, "Study of Surface Roughness and Cutting force in machining for 6068 Aluminium alloy," in IOP Conference Series: Materials Science and Engineering, 2018, vol. 346, no. 1.

[12] C. Shoba, N. Ramanaiah, and D. Nageswara Rao, "Effect of reinforcement on the cutting forces while machining metal matrix composites-An experimental approach," Eng. Sci. Technol. an Int. J., vol. 18, no. 4, pp. 658-663, 2015.

[13] T. L. Schmitz and K. S. Smith, Machining dynamics : frequency response to improved productivity. Springer, 2009.

[14] S. Kalpakjian, Manufacturing engineering and technology. Pearson Education India, 2001.

[15] J. Qiu, "Modeling of cutting force coefficients in cylindrical turning process based on power measurement," Int. J. Adv. Manuf. Technol., vol. 99, no. 2, pp. 2283-2293, Dec. 2018.

[16] Mohamad Farizal Rajemi, "Energy Analysis in Turning and Milling," Manchester, 2010.

[17] L. Meng, M. Zhou, C. Zhang, and G. Tian, "A new model for predicting power consumption of machining processes: A turning case," IEEE International Conference on Automation Science and Engineering, vol. 2016-Novem. pp. 1289-1294, 2016.

[18] M. C. Shaw, Metal cutting principles. Oxford University Press, 2005.

[19] A. P. S. V. R. Subrahmanyam, G. Narsaraju, and B. S. Rao, "Effect of Rice Husk ash and Fly ash Reinforcements on Microstructure and Mechanical properties of Aluminium alloy (AlSi10Mg) Matrix Composites," Int. J. Adv. Sci. Technol., vol. 76, no. September, pp. 1-8, 2015. 
[20] C. G. Ozoegwu, "Stabilizing wave attenuation effects in turning process," http://mc.manuscriptcentral.com/tpmr, vol. 2, no. 1, pp. 2-10, Jan. 2014. 